\title{
Chapter 11 \\ Where and when to Use Induction \\ Chemotherapy in Head and Neck Squamous Cell Cancer
}

\author{
Jan B. Vermorken
}

\section{Introduction}

Worldwide cancer incidence and mortality are rapidly growing, and this is also true for head and neck squamous cell cancer (HNSCC). The 2018 estimates point at more than 750.000 new cases and more than 380.000 deaths [1]. The reasons are complex but reflect both aging and growth of the population, as well as changes in the prevalence and distribution of the main risk factors for cancer, several of which are associated with socioeconomic development [2, 3]. Sustained exposure to tobacco, tobacco-like products, and alcohol increase the risk of developing HNSCC [4]. Although HNSCC can arise within the oral cavity, oropharynx, hypopharynx, larynx, and nasopharynx, there has been a shift in primary site distribution, with a steady increase of oropharyngeal squamous cell carcinoma (OPSCC) and a decline in cancers of the larynx and hypopharynx, in particular in the Western world [5]. This change has been observed in parallel with a decrease in cigarette smoking and the identification of exposure to high-risk oncogenic human papillomavirus (HPV) as a risk factor for the development of OPSCC $[6,7]$. This possible role for HPV in head and neck cancer was first reported in the 1990s, while the proof for a causal association between HPV and OPSCC was delivered in 2000 [8, 9]. A systematic review and meta-analysis showed that the overall HPV prevalence in OPSCC is increasing significantly over time: from $40.5 \%$ (95\% CI,35.1-46.1) before 2000, to $64.3 \%$ (95\% CI, 56.7-71.3) between 2000 and 2004, and 72.2\% (95\% CI, 52.9-85.7) between 2005 and 2009 ( $<$ <.001) [10]. Prevalence increased significantly initially in North America and subsequently in Europe, and the significant gap between them that existed before 2000 (50.7\% vs 35.3\%, respectively, $\mathrm{p}=.008$ ) has now disappeared $(69.7 \%$ vs $73.1 \%$, respectively, $\mathrm{p}=.8)$.

\footnotetext{
J. B. Vermorken $(\bowtie)$

Department of Medical Oncology, Antwerp University Hospital, Edegem, Belgium and Faculty of Medicine and Health Sciences, University of Antwerp, Antwerp, Belgium e-mail: JanB.Vermorken@uza.be
} 
Many earlier studies have observed that patients with HPV-positive OPSCC had a distinct epidemiology when compared to patients with HPV-unrelated OPSCC, i.e. they were statistically younger, were more likely male, had fewer comorbidities, and reported less tobacco exposure but higher numbers of (oral) sex partners [1113]. The prognosis for these younger patients with HPV-positive OPSCC was substantially better than that for patients with HPV-negative tobacco-related cancers treated similarly [5]. However, more recently, several studies portend that the population of elderly patients with HPV-positive OPSCC is expanding [14-16]. In fact, the age at OPSCC diagnosis is increasing for both HPV-positive and HPV-negative patients, and a rising proportion of older patients have HPV-positive tumors. In an analysis of the National Cancer Database (with 119,611 OPSCC patients) Rettig et al. [14] showed that although patients of $\geq 70$ years of age with HPV-positive OPSCC had improved survival compared to those with HPV-negative OPSCC (adjusted hazard ration $[\mathrm{aHR}]=0.65,95 \% \mathrm{CI}=0.55-0.76$ ), the survival benefit of HPV-positive tumor status was significantly attenuated compared to younger HPVpositive patients $\left(50-59\right.$ years: $\left.\mathrm{aHR}=0.45,95 \% \mathrm{CI}=0.39-0.51 ; \mathrm{p}_{\text {interaction }}<0.001\right)$. The outcome of these older patients with HPV-positive OPSCC was in fact essentially similar to survival for the young HPV-negative patients [14]. These data will have implications for the therapeutic approach that clinicians need to consider for these elderly patients, taking into account the higher comorbidity score, the distinct disease characteristics, the higher rates of treatment-related toxicities, and the increased risk of non-cancer-related deaths [14].

\section{Milestones in Systemic Therapies for Locoregionally Advanced HNSCC}

Before 1980, the initial treatment of patients with locoregionally advanced stage III or IV (M0) was surgery and/or radiation therapy (RT), a choice that depended on the site of the disease, the resectability of the cancer, the performance status of the patients, and his/her comorbidities. However, with these "traditional" therapies outcome was quite poor, in particular in those with stage IV or unresectable disease. The milestones in systemic therapies are summarized in Fig. 11.1.

Single agent chemotherapy, in particular methotrexate was used for palliation in patients with recurrent or metastatic disease already in the 1960s. Systemic therapy was introduced as part of combined modality therapy for LA-HNSCC in the mid 1970s, initially as single agent chemotherapy with methotrexate or cisplatin, usually with palliative intent to patients with stage IV disease, M1 cancers or recurrent disease beyond salvage local treatment [17]. The utilization of cisplatin as a single agent produced a range of responses from $14 \%$ to $41 \%$ [18]. The higher response rates were seen in previously untreated patients. Subsequently, experience was obtained with combination chemotherapy, initially with cisplatin/bleomycin combinations, to which then methotrexate or vinca-alkaloids were added and ultimately 
Fig. 11.1 Milestones in systemic therapy $( \pm$ TRT) in head and neck squamous cell cancer 1960s

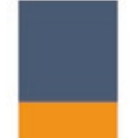

1970s

1980s

1990s

2000s
Single agent chemotherapy

Methotrexate

Combination chemotherapy regimens

Platinum compounds

Larynx preservation

Induction chemotherapy (ICT)

Concurrent CRT standard (CCRT)

Taxanes

De-escalation trials in HPV+ OPC

ICT revisited

Targeted therapy / Immunotherapy

Table 11.1 Induction chemotherapy in locoregionally advanced HNSCC*

\begin{tabular}{l|l|l|l|l}
\hline Type of induction Chemotherapy & No. of patients & CR No. (\%) & PR No. (\%) & OR No. (\%) \\
\hline Single MTX, BLM or P & 188 & $4(2)$ & $81(43)$ & $85[45]$ \\
\hline Combo PB & 467 & $34(7)$ & $193(41)$ & $227(48)$ \\
\hline Combo PBM & 323 & $51(16)$ & $187(58)$ & $238(74)$ \\
\hline Combo PB-Vinca & 474 & $96(20)$ & $231(49)$ & $327(69)$ \\
\hline Combo PF & 461 & $162(35)$ & $236(51)$ & $398(86)$ \\
\hline Combo P-other & 445 & $89(20)$ & $236(53)$ & $325(73)$
\end{tabular}

$M T X$ metrotrexate, $B L M$ bleomycin, $P$ cisplatin, $P B$ cisplatin/bleomycin, $P B M$ PB + MTX, Vinca vinca alkaloid, $P F$ cisplatin/infusional 5-FU, $C R$ complete response, $P R$ partial response, $O R$ overall response. *modified from Choski et al. [19]

the cisplatin/infusional 5-fluorouracil (5-FU) regimen [19; Table 11.1). At Wayne State University in 1977, they initiated a pilot study for advanced previously untreated patients with head and neck cancer utilizing cisplatin, vincristine, and bleomycin. An overall response rate of $80 \%$ was achieved, with a $29 \%$ complete response $(\mathrm{CR})$ rate [18]. With the known pulmonary toxicity of bleomycin and the in vitro synergism of 5-FU and cisplatin, they started a second pilot study with cisplatin $\left(100 \mathrm{mg} / \mathrm{m}^{2} \mathrm{IV}\right.$, day 1$)$ and $5-\mathrm{FU}\left(1000 \mathrm{mg} / \mathrm{m}^{2} /\right.$ day by continuous IV infusion over 96 hours), the so-called PF regimen. The response rate with that regimen was $88 \%$ overall, with a $19 \% \mathrm{CR}$ rate [20]. Increasing the infusion time of 5-FU to $120 \mathrm{hrs}$ and the number of courses from 2 to 3, increased the overall response rate to $93 \%$ and the CR rate to $54 \%$ [21]. The feasibility of the latter scheme was established and the efficacy confirmed in a multi-institutional study within the Radiation Therapy Oncology Group (RTOG). An overall response rate of $86 \%$ was obtained, with a $38 \% \mathrm{CR}$ rate [22]. An attempt to further improve the regimen by using higher dosages of cisplatin $\left(40 \rightarrow 30 \mathrm{mg} / \mathrm{m}^{2} /\right.$ day $\times 5$ for 3 cycles), given in hypertonic saline, failed to show any further improvement over the $120 \mathrm{hrs}$ PF regimen [23]. Although non-randomized trials were very promising with respect to response rate and sometimes also suggesting an improvement of survival, the impact on survival could only be assessed in randomized trials. Five randomized trials executed 
between 1979 and 1987 using methotrexate as a single agent for induction before local treatment were, apart from one study, all negative with respect to survival benefit [24]. In the single positive study the methotrexate had been administered intra-arterially. Looking in more detail at that study, a difference in survival was present only in patients with oral cavity cancer. Further analysis of the oral cavity cases showed that the 5-year survival difference had significance only in stage II patients. The very high response rates, and in particular the very high CR rates stimulated investigators to do randomized trials with the hope to improve survival. However, the disappointment came rather fast when early randomized trials were all negative with respect to survival benefit, apart from one in patients with oral cavity cancer, in which again chemotherapy was administered by the intra-arterial route [24]. However, apart from a high response rate in untreated patients with locoregionally advanced HNSCC, it became clear that those patients that responded well to chemotherapy subsequently also responded more favorably to radiotherapy (RT) [25]. This observation formed the rationale for the first-generation larynx preservation trials (see below).

In the 1990s, with the disappointing results with respect to survival gain in many randomized trials utilizing induction chemotherapy (ICT), the concept of concurrent chemotherapy with radiation therapy was revisited with the introduction of cisplatin given concurrently with radiation as the primary treatment for patients with inoperable and/or unresectable head and neck cancers [26]. The large individual patient-based meta-analysis, reported in 2000, demonstrated that cisplatin given concurrently with radiation ( $100 \mathrm{mg} / \mathrm{m}^{2}$ on days 1,22 , and 43 of the RT) achieved substantially more survival benefit versus RT alone when cisplatin was given sequentially (before or after the radiation) [27, 28; Table 11.2]. That is also true for the comparison versus the at that moment considered to be the best type of ICT, i.e. the PF regimen. Since that time enthusiasm to use ICT diminished strongly and colleagues on both sides of the Atlantic started to accept concurrent cisplatin-based chemoradiotherapy (CCRT) as the preferred treatment for both patients with resectable disease and those with inoperable or unresectable disease. For the first category of patients, i.e. those with resectable disease, it was used as an adjuvant CCRT in case there were unfavorable features in the pathology specimen (positive margins and/or extracapsular extension), in the second category it was used as a definitive nonsurgical treatment (definitive CCRT). Determinative in this change of attitude

Table 11.2 Summary of the meta-analysis of the MACH-NC collaborative Group [27, 28]

\begin{tabular}{l|l|l|l|l|l}
\hline Trial category & $\begin{array}{l}\text { No. of } \\
\text { trials }\end{array}$ & $\begin{array}{l}\text { No. of } \\
\text { patients }\end{array}$ & $\begin{array}{l}\text { Absolute benefit at } \\
5 \text { years }\end{array}$ & $\begin{array}{l}\text { Risk } \\
\text { reduction }\end{array}$ & P value \\
\hline All trials & 65 & 10,850 & $4 \%$ & $10 \%$ & $<0.0001$ \\
\hline Adjuvant & 8 & 1854 & $1 \%$ & $2 \%$ & 0.74 \\
\hline Induction & 31 & 5269 & $2 \%$ & $5 \%$ & 0.10 \\
\hline $\begin{array}{l}\text { Induction with } \\
\text { PF }\end{array}$ & 15 & 2487 & $5 \%$ & $12 \%$ & 0.01 \\
\hline Concomitant & 26 & 3727 & $8 \%$ & $19 \%$ & $<0.0001$ \\
\hline
\end{tabular}

$P F$ cisplatin +5 -fluorouracil combination 
were four large randomized controlled trials which irrefutably showed benefit of this combined modality approach [29-32].

The first two decades in 2000 are fascinating in that new treatment approaches, initially targeted therapies, but later also immunotherapies came forward [33-40]. Both targeted therapies (in particular cetuximab) and immunotherapies (especially immune checkpoint inhibitors [CPIs]) have been practice changing. Not only were they extensively studied in the recurrent/metastatic (R/M) disease setting [34, 3840], they also found their way in patients with LA-HNSCC $[35,36]$, although for CPIs that has not been fully developed yet. There arose a renewed interest in ICT since the introduction of the taxanes, which proved to be active compounds for this disease [41, 42]. Two randomized controlled trials (RCTs), one in the US and one in Europe, showed that adding docetaxel to the PF combination made this regimen more efficacious, better tolerable for the patients, did not lead to a negative effect on quality of life (QoL), and was cost-effective [43-46]. This so-called TPF regimen is now considered standard for those situations in which ICT is indicated.

\section{Comparison of the Practice Changing TPF Protocols (TAX 323/EORTC 24971 and TAX 324)}

The results of the European TPF regimen (protocol TAX 323/EORTC 24971) and the American TPF regimen (TAX 324) were published back to back in the New England Journal of Medicine in 2007 [43, 44]. In both phase III trials, LA-HNSCC patients were randomized to receive three (TAX 324) or four (TAX 323/EORTC 24971) cycles of TPF or PF as induction before local treatments. Details on the respective regimens can be found in Table 11.3. The studies were executed in different patient populations. TAX 323/EORTC 24971 included only patients with previously untreated, unresectable LA-HNSCC, while in TAX 324 there was a mixture of patients involved, i.e. those with either unresectable disease or disease of low surgical curability, as well as patients with LA-HNSCC who were candidates for organ preservation. Both studies also differed in the local treatment part of the protocol following the induction phase. In TAX 323/EORTC 24971, patients who did not have progressive disease underwent conventionally fractionated RT within 4 to 7 weeks after the completion of chemotherapy (total dose, 66 to 70 Gy) or accelerated or hyperfractionated regimens (total maximum dose $70 \mathrm{~Gy}$ for the accelerated

Table 11.3 TPF regimens in accordance with TAX 323/E ORTC 24971 and TAX 324

\begin{tabular}{|c|c|}
\hline Study & TPF regimen \\
\hline $\begin{array}{l}\text { TAX 323/EORTC } 24971 \text { [44] } \\
\text { - four cycles of TPF }\end{array}$ & $\begin{array}{l}\text { Docetaxel }\left(75 \mathrm{mg} / \mathrm{m}^{2}\right) \text { as a } 1 \text {-hour infusion on day } 1 \\
\text { Cisplatin }\left(75 \mathrm{mg} / \mathrm{m}^{2}\right) \text { as a } 1 \text {-hour infusion on day } 1 \\
5 \text {-FU }\left(750 \mathrm{mg} / \mathrm{m}^{2} / \text { day }\right) \text { by continuous IV infusion, day } 1-5\end{array}$ \\
\hline $\begin{array}{l}\text { TAX } 324[43] \\
\text { - three cycles TPF }\end{array}$ & $\begin{array}{l}\text { Docetaxel }\left(75 \mathrm{mg} / \mathrm{m}^{2}\right) \text { as a } 1 \text {-hour infusion on day } 1- \\
\text { Cisplatin }\left(100 \mathrm{mg} / \mathrm{m}^{2}\right) \text { over a period of } 0.5-3 \text { hours } \\
5 \text {-FU }\left(1000 \mathrm{mg} / \mathrm{m}^{2} / \text { day }\right) \text { by continuous IV infusion, day } 1-4\end{array}$ \\
\hline
\end{tabular}


regimen and 74 Gy for the hyperfractionated regimen), decided before the start of the protocol for each institution. Neck dissections could be performed, if indicated, before or after the RT. In TAX 324, all patients were assigned to receive CCRT beginning 3 to 8 weeks after the start of the third cycle of ICT (day 22 to day 56 of cycle 3 ). Weekly carboplatin at an area under the curve of 1.5 was given as an intravenous infusion during a 1-hour period for a maximum of seven weekly doses during the course of RT. The definitive curative radiation dose administered to the primary tumor was between 70 and $74 \mathrm{~Gy}$, administered as fractions of 2 Gy per day 5 days per week. The dose administered to uninvolved lymph nodes was at least $50 \mathrm{~Gy}$. Involved lymph nodes were to receive 60 to $74 \mathrm{~Gy}$, depending on whether an elective neck dissection was indicated after completion of treatment. Surgery was performed 6 to 12 weeks after completion of chemoradiotherapy in patients who had an initial nodal stage of N2 and a partial response to ICT or N3 disease, or residual disease after chemoradiotherapy. Surgery was also allowed for patients who did not complete chemoradiotherapy and had resectable residual disease at the primary site or in the neck.

Both trials concluded that the overall response rate with TPF was significantly (TAX 323/EORTC 24971) or numerically (TAX 324) higher than with PF. Both TPF regimens also clearly demonstrated survival benefit over PF ICT (Fig. 11.2). About three-quarters of the patients completed both TPF and RT per protocol and $24 \%$ to $29 \%$ had treatment delays during ICT. As mentioned above, the TAX 323/ EORTC 24971 regimen was associated with a more favorable safety profile than the previously standard PF regimen, likely owing to the lower overall doses of the cisplatin $\left(75 \mathrm{mg} / \mathrm{m}^{2}\right.$ instead of $100 \mathrm{mg} / \mathrm{m}^{2}$ on day 1$)$ and $5-\mathrm{FU}\left(750 \mathrm{mg} / \mathrm{m}^{2} /\right.$ day $\mathrm{x} 5$ instead of $1000 \mathrm{mg} / \mathrm{m}^{2} /$ day $\mathrm{x} 5$ ). This resulted in a lower frequency of grade $3 / 4$ stomatitis, nausea/vomiting, dysphagia, and thrombocytopenia [44]. Patients in the
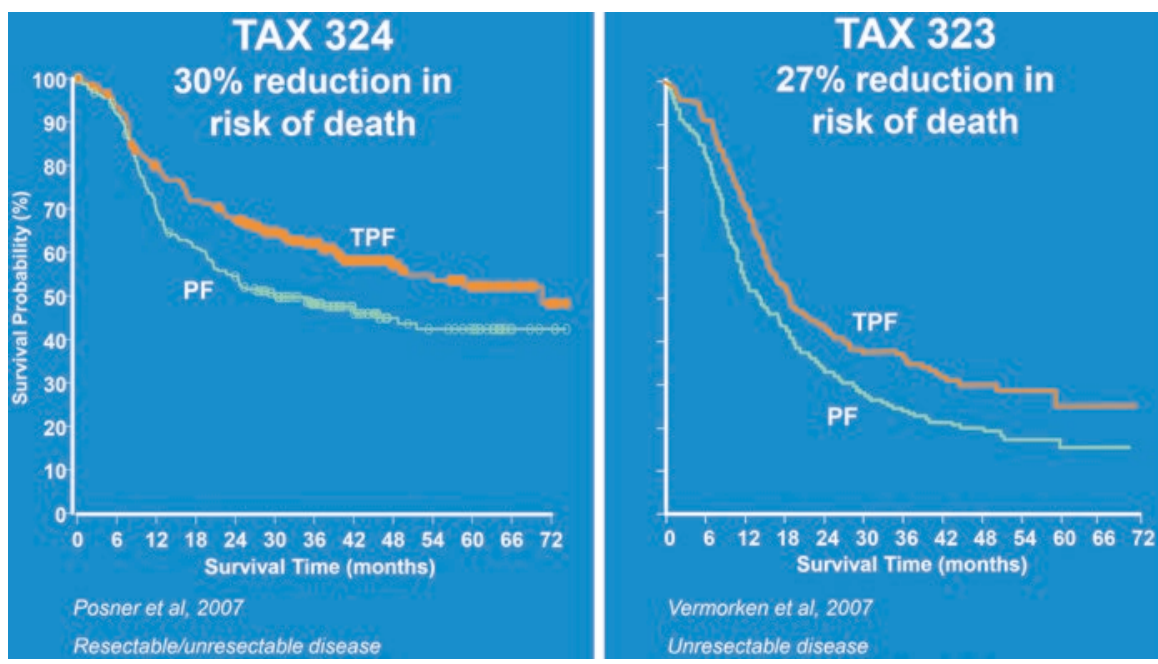

Fig. 11.2 Landmark trials of TPF versus PF in locoregionally advanced HNSCC 
TPF arm had fewer treatment delays then did those in the PF group despite differences in peak neutropenia during ICT in the TPF group [43,44]. The superiority of TPF over PF has been confirmed in a meta-analysis of pooled data from five phase III studies, including the two mentioned above [47]. This analysis concluded that the TPF regimen, compared to the PF regimen, led to benefits in progression-free survival (PFS), overall survival (OS), locoregional failure rate (LFR) and distant failure rate (DFR). Nevertheless, despite the fact that this meta-analysis confirmed that TPF was a better ICT than PF, some critical remarks were made with respect to the pooling methodology used on the five rather heterogeneous studies, the missing treatment failure data in the participating two Spanish trials $[48,49]$ and the EORTC trial [44], and the different follow-up treatments that were applied for the ICT responders and the ICT non-responders [50]. However, what this meta-analysis did not do, was changing the standard of care in patients with advanced HNSCC, i.e. concurrent chemoradiotherapy.

The main question that remained for most clinicians was not whether TPF was superior to PF, there was a unanimous feeling about that, but it was whether the sequential use of ICT and local therapy was superior to the concurrent use of chemotherapy and radiation. Although two previous phase III studies demonstrated benefit for ICT $\rightarrow$ RT versus RT alone, in particular in patients with inoperable/ unresectable disease [51, 52], the role of ICT in connection to CCRT in patients with inoperable/unresectable disease remained controversial, due to difficulties in trial design, execution or insufficient patient accrual [53-57]. However, what most of these studies had in common was the fact that the toxicity with the combined approach was increased. Febrile neutropenia could be found as high as 11\% [53] and toxic deaths have been reported even up to 6\% [57]. Moreover, the use of ICT could compromise the completion of subsequent chemoradiation, which can have a deleterious effect, not only on local control, but also on survival [58]. Therefore, less toxic schemes have been investigated, such as a modified TPF regimen [59], a weekly carboplatin (AUC2) and paclitaxel $\left(135 \mathrm{mg} / \mathrm{m}^{2}\right)$ regimen for six consecutive weeks [60] and the TPEx regimen (docetaxel and cisplatin both $75 \mathrm{mg} / \mathrm{m}^{2}$ every three weeks for three cycles plus weekly cetuximab $400 / 250 \mathrm{mg} / \mathrm{m}^{2}$ ) [61] are all of interest. A randomized controlled trial comparing TPF to modified TPF in fit patients is currently ongoing [62].

\section{When to Use Induction Chemotherapy in Head and Neck Squamous Cell Cancer}

\section{For Larynx Preservation}

There is an established role for ICT in larynx preservation programs for patients who otherwise would be candidates for total laryngectomy. When Wayne State University published its positive experience with the PF regimen in previously 
untreated patients with head and neck cancers [21] and thereafter showed that responders nearly all (97\%) were controlled by subsequent radiation, and the others did much less [25], an new concept of treatment was born, i.e. using ICT as a selection procedure. This concept was first tested in randomized trials with in the control arm patients that received the standard of care at that time, i.e. total laryngectomy with postoperative RT, and in the experimental arm patients that were treated with PF ICT followed in responders by RT and salvage surgery if required. These first generation trials are summarized in Table 11.4. The conclusions of these two trials were that the concept of larynx preservation, with the use of ICT as a selection procedure, was safe, kept the larynx in place in about two thirds of the patients and had no negative impact on survival [63-66]. The next generation of larynx preservation trials did not look only to how many larynxes could be kept in place, but took more notice of the function of the larynx. In that context a new definition of larynx preservation came forward "laryngoesophageal dysfunction-free survival" that included death, local failure, salvage laryngectomy, tracheotomy, or feeding tube at 2 years or later [67].

With the milestone of concurrent chemoradiotherapy in the second half of the 1990s (see above) next trials compared ICT followed by RT with CCRT or with alternating CT and RT [68-71]. The results of these studies are summarized in Table 11.5.

Table 11.4 Induction chemotherapy trials for larynx preservation: first generation

\begin{tabular}{l|l|l|l|l|l}
\hline Study Group & $\begin{array}{l}\text { Tumor size } \\
\text { and stage }\end{array}$ & Treatment arms & $\begin{array}{l}\text { No. of } \\
\text { pts }\end{array}$ & $\begin{array}{l}\text { Survival (at 5 \& } \\
10 \text { years) }\end{array}$ & LP \\
\hline VA & Larynx & TL + RND + RT & 332 & $45 \% \& 30 \%$ & \\
\hline $1991[63]$ & T1-T4, N2-3 & PF $\times 3 \rightarrow$ RT $^{\mathrm{a}}$ & & $42 \% \& 25 \%$ & $64 \%$ \\
\hline EORTC & Hypopharynx & TL + RND + RT & 202 & $33 \% \& 14 \%$ & \\
\hline $1996,2012[64,65]$ & T2-T4, N0-3 & PF $\times 3 \rightarrow$ RT $^{\mathrm{a}}$ & & $38 \% \& 13 \%$ & $62 \%$ \\
\hline
\end{tabular}

$V A$ Veterans Affairs Laryngeal Cancer Study Group, $L P$ larynx preservation, $T L$ total laryngectomy, $R N D$ radical neck dissection, $R T$ radiotherapy, $P F$ cisplatin $100 \mathrm{mg} / \mathrm{m}^{2} \mathrm{~d} 1+5-\mathrm{FU} 1000 \mathrm{mg} /$ $\mathrm{m}^{2}, \mathrm{~d} 1-5$

${ }^{a}$ The non-responders received surgery $+\mathrm{RT}$

${ }^{b} \mathrm{~N} 2 \mathrm{c}$ was excluded

Table 11.5 Induction chemotherapy trials for larynx preservation: second generation

\begin{tabular}{|c|c|c|c|c|c|}
\hline Study Group & $\begin{array}{l}\text { Tumor size and } \\
\text { stage }\end{array}$ & Treatment arms & $\begin{array}{l}\text { No.of } \\
\text { pts }\end{array}$ & $\begin{array}{l}\text { Survival (at } 5 \\
\& 10 \text { years) }\end{array}$ & $\begin{array}{l}\text { LP (10 } \\
\text { years) }\end{array}$ \\
\hline RTOG 91-11 & $\begin{array}{l}\text { Glottic and } \\
\text { supraglottic }\end{array}$ & $\mathrm{PF}^{1} \times 3 \rightarrow \mathrm{RT}$ & 173 & $58 \% \& 39 \%$ & $68 \%{ }^{a}$ \\
\hline \multirow[t]{2}{*}{$2003,2013[70,71]$} & $\mathrm{N} 0-1, \mathrm{~N} 2, \mathrm{~N} 3$ & CCRT (cisplatin) & 172 & $55 \% \& 28 \%$ & $82 \%{ }^{a}$ \\
\hline & $\mathrm{T} 2, \mathrm{~T}^{+}, \mathrm{T} 3-\mathrm{T} 4$ & RT & 173 & $54 \% \& 32 \%$ & $64 \%$ \\
\hline EORTC 24954 & $\begin{array}{l}\text { Larynx and } \\
\text { hypophar. }\end{array}$ & $\mathrm{PF}^{1} \times 2-4 \rightarrow \mathrm{RT}$ & 224 & $49 \% \& 34 \%$ & $56 \%^{\mathrm{b}}$ \\
\hline $2009,2016[68,69]$ & T2-T4, N0-N2 & $\mathrm{PF}^{2}$ alternate with RT & 226 & $52 \% \& 32 \%$ & $56 \%^{\mathrm{b}}$ \\
\hline
\end{tabular}

$L P$ larynx preservation, $P F 1$ cisplatin $100 \mathrm{mg} / \mathrm{m}^{2}, \mathrm{~d} 1+5-\mathrm{FU} 1000 \mathrm{mg} / \mathrm{m}^{2}, \mathrm{~d} 1-5, C C R T$ concurrent chemoradiotherapy, $R T$ radiotherapy, $P F 2$ cisplatin $20 \mathrm{mg} / \mathrm{m}^{2} / \mathrm{d}, \mathrm{d} 1-5+5-\mathrm{FU} 200 \mathrm{mg} / \mathrm{m}^{2} / \mathrm{d} 1$, d1-5, T3+ with fixed cord involvement, T3- without cord fixation

${ }^{a} L P$ larynx in place, function (voice quality, swallowing function, QoL questionnaire) evaluated

${ }^{\mathrm{b}} L P$ larynx in place, no tumor, no tracheotomy, no feeding tube 
The alternating arm in the EORTC trial had a lower dose of 5-FU (total $1000 \mathrm{mg} / \mathrm{m}^{2}$ instead of $5000 \mathrm{mg} / \mathrm{m}^{2}$ per cycle) and a lower total dose of radiation (60Gy instead of $70 \mathrm{~Gy})$. This resulted in less grade 3 or 4 mucositis $(32 \%$ in the sequential arm vs $21 \%$ in the alternating arm) and late severe edema and/or fibrosis was observed in $16 \%$ of the patients in the sequential arm versus $11 \%$ in the alternating arm. No significant differences in outcome between the two arms of the study were observed. Combined with the toxicity data the results favored slightly the alternating arm. However, due to the organizational difficulties in delivering this alternating regimen in daily practice, this regimen is rarely used [66, 68, 69]. RTOG 91-11 is a crucial trial, in that it is the only trial that compares sequential treatment $(\mathrm{PF} \rightarrow \mathrm{RT})$ with cisplatin-based CCRT and a RT alone arm [70, 71]. There have been several analyses reported, all showing a higher larynx preservation rate with the CCRT arm compared with the ICT arm or the RT alone arm. At the long-term follow-up analysis, both chemotherapy regimens significantly improved laryngectomy-free survival (LFS; primary endpoint) compared with RT alone. Overall survival did not differ significantly, although there was a possibility of worse outcome with CCRT relative to ICT (HR, 1.25; 95\% CI, 0.98 to $1.61 ; \mathrm{P}=.08$ ). No difference in late effects was detected, but for deaths not related to the study cancer, there was a significant disadvantage for the CCRT group compared to the ICT group $(52.8 \%$ vs $69.8 \%$, respectively, $\mathrm{p}=0.03$ ).

With the revival of ICT in the first decade of the twenty-first century, it was to expect that the comparison of TPF versus PF would also be studied in the larynx preservation setting. This was executed by the GORTEC (Groupe Oncologie Radiotherapie Tete Et Cou) in a phase III protocol [72]. Protocol 2000-1 was conducted in 220 patients with locoregionally advanced laryngeal and hypopharyngeal cancer, who were eligible for total laryngectomy. The European TPF schedule was compared with the standard PF regimen and three cycles at a 3-week interval were planned. The primary endpoint of the study was larynx preservation and larynx preservation was defined as a larynx in place without tumor, tracheostomy or feeding tube. Ultimately, 213 patients were treated with a median follow-up of 105 months $[72,73]$. The larynx preservation rate was significantly higher with TPF than with PF (at 10 years $70.3 \%$ versus $46.5 \%, \mathrm{P}=.01$ in the TPF vs PF arms, respectively). The 10-year laryngeal dysfunction-free survival was $63.7 \%$ with TPF and $37.2 \%$ with PF, which was again significantly different [73]. There was no significant difference in 5-year or 10-years OS, or disease-free survival (DFS). Statistically fewer grade 3-4 late toxicities occurred with the TPF regimen compared with the PF arm $(9.3 \%$ vs $17.1 \%, \mathrm{P}=.038)$. Support for this observation comes from a subgroup analysis of the TAX 324 study, that included only patients with advanced laryngeal and hypopharyngeal cancer. Among those that had operable disease (TPF, $\mathrm{n}=67$; PF, $\mathrm{n}=56$ ), LFS was significantly greater with TPF (HR: 0.59; 95\% CI: $0.37-0.95 ; \mathrm{P}=0.030$ ). Three-year LFS with TPF was $52 \%$ versus $32 \%$ for PF [74].

For larynx preservation ICT with TPF is one of the two approaches that can be considered as a standard approach for patients with advanced laryngeal or hypopharyngeal cancer, who are not eligible for partial laryngectomy. The 
other approach is cisplatin-based CCRT. Overall, T4 disease and tumors extending to the post-cricoid area are not eligible for larynx preservation. It is unclear for the moment which option is best. The two approaches are presently being compared in the ongoing SALTORL trial (GORTEC 2014-03).

\section{For Treatment Intensification}

As mentioned earlier, the main question that remained for most clinicians was whether the use of TPF before the cisplatin-based CCRT would lead to survival benefit. The background for that can be found in the individual patient-based metaanalysis (MACH-NC) by Pignon et al., initially published in 2000, but updated in 2009 [75]. In that analysis, a 6.5\% 5-year absolute survival benefit was demonstrated for the concurrent chemotherapy/RT approach [75]. No overall survival benefit was observed with the ICT schedules, although a marginal improvement was noticed in trials that made use of the PF combination. Patterns of failure differed between the two approaches. ICT significantly improved the rate of distant metastases (HR, 0.73; 95\% confidence interval [CI] 0.61 to $0.88 ; \mathrm{p}=.001$ ), but did not influence locoregional failure. However, CCRT markedly improved locoregional control (HR, $0.74 ; 95 \% 0.70$ to $0.79 ; \mathrm{p}<.001)$ with a significant but less impressive improvement in distant control (HR, $0.88 ; 95 \% \mathrm{CI}, 0.77$ to $1.00 ; \mathrm{p}=.04$ ). It seemed therefore reasonable to assume that combining both approaches could have a complementary effect on outcome. The five randomized controlled trials that compared ICT $\rightarrow$ CCRT versus CCRT alone are summarized in Table 11.6 [53-57]. Four of the five trials showed no impact of ICT on survival. The Italian study (with two types of concomitant regimens, cisplatin/5-FU + RT or cetuximab + RT) did show a survival benefit, but subgroup analysis did not show benefit for patients who received potentiation with cisplatin and fluorouracil. Two trials had accrual problems and stopped early before reaching the required number of patients, and two studies had difficulties in trial design or trial performance. Therefore, the role of ICT given before CCRT on the basis of these five trials still remains controversial.

Two meta-analyses on the usefulness of ICT before CCRT in patients with LA-HNSCC concluded that, although ICT reduced the occurrence of distant failures, this did not translate into a significant survival benefit [76, 77]. However, the most recent systematic review and Bayesian network meta-analysis, comprising 57 trials and 15,723 patients indicated that IC with TPF was significantly superior against CCRT with cisplatin (HR 0.73 95\% credible interval [CrI] 0.58-0.92) [78]. Therefore, it seems that over time, more data are pointing at a real value of the TPF regimen when used in addition to cisplatin-based CCRT. However, as indicated above, individual randomized studies so far have not given an clear answer as to whether ICT is useful for treatment intensification in daily practice. Therefore, further positioning of ICT with CCRT as standard treatment for LA-SCCHN will come from more RCTs directly comparing ICT $\rightarrow$ CCRT with CCRT in the appropriate patient population. 
Table 11.6 Randomized trials of induction chemotherapy followed by concurrent chemoradiotherapy versus concurrent chemoradiotherapy alone in patients with locoregionally advanced HNSCC

\begin{tabular}{|c|c|c|c|c|}
\hline Investigators/Trial & Population & Regimens & Survival $\uparrow$ & Tox $\uparrow$ \\
\hline \multirow[t]{2}{*}{ Hitt et al/TTCC [53] } & 439 pts, stage III/IV & TPF (or PF)x3 $\rightarrow$ CCRT(P) & No & Yes \\
\hline & Prim. endpoint: PFS & CCRT (cisplatin) & & \\
\hline \multirow{2}{*}{$\begin{array}{l}\text { Haddad et al/ } \\
\text { PARADIGM [54] }\end{array}$} & 145 pts, N2 and N3 & TPFx3 $\rightarrow$ CCRT (C or Doce) & No & Yes \\
\hline & Prim. endpoint: OS & CCRT (cisplatin) & & \\
\hline \multirow{2}{*}{$\begin{array}{l}\text { Cohen et al/DeCIDE } \\
\text { [55] }\end{array}$} & 285 pts, N2 and N3 & TPFx2 $\rightarrow$ CCRT (THF) & No & Yes \\
\hline & Prim. endpoint: OS & CCRT (THF) & & \\
\hline \multirow[t]{2}{*}{ Ghi et al./GSTTC [56] } & 421 pts, stage III/IV & CCRT(PF) w/wo prior TPF & Yes $^{\mathrm{a}}$ & Yes $^{b}$ \\
\hline & Prim. endpoint: OS & BRT(cet.) w/wo prior TPF & & \\
\hline \multirow{2}{*}{$\begin{array}{l}\text { Geoffrois et al./GORTC } \\
2007-02 \text { [57] }\end{array}$} & 370 pts, N2b/c, N3 & TPFx3 $\rightarrow$ BRT (cetuximab) & No & Yes \\
\hline & $\begin{array}{l}\text { Prim. endpoint: } \\
\text { 2-yPFS }\end{array}$ & CCRT (carbo/5-FU) & & \\
\hline
\end{tabular}

$T$ docetaxel, $P$ cisplatin, $F$ 5-fluorouracil, $C C R T$ concurrent chemoradiotherapy, $C$ carboplatin, Doce docetaxel, Cet cetuximab, THFX docetaxel, fluorouracil and hydroxyurea, BRT bioradiation with cetuximab

aPFS and OS were significantly better in the ICT arms, but subgroup analysis did not show any benefit for patients who received radiation with cisplatin and 5-FU after TPF

${ }^{b}$ More severe neutropenia in the ICT arms, other toxicities were not significantly different

Results from the DeCIDE trial and the GORTEC 2007-02, showing fewer distant metastases in the ICT arm of the studies, suggest that there still may be patients at very high risk for developing distant metastases who could benefit from ICT. Some improvement in the $\mathrm{N}$-staging in the most recent American joint Committee in Cancer staging system has been made. Features such as low neck nodes and matted nodes (a proxy for extranodal extension) are of interest in that respect. In a retrospective analysis of 321 patients treated with three cycles docetaxel/cisplatin ICT followed by CCRT (weekly cisplatin), Kim et al. reported that lower neck node involvement (level IV, Vb, and supraclavicular regions) $(\mathrm{p}=0.008)$ and poor response to ICT $(\mathrm{p}<0.001)$ were associated with a significantly inferior distant metastasis-free survival [79].

In contrast to the patterns of failure seen in p16-negative disease, distant failure constitute a considerable portion of treatment failures in patients with p16-positive disease [80]. The Toronto group, in their analysis, pointed at patients with T4 and $\mathrm{N} 3$ disease being at high risk for distant failure. In a retrospective study, comprising patients with p16-positive OPSCC with low-neck (level IV and/or Vb) and/or N3 lymphadenopathy, being at high risk of distant failure, 44 receiving ICT (docetaxel/ platinum w/wo 5-FU) followed by CCRT (43 receiving platinum, 1 cetuximab) were compared with 44 patients receiving CCRT alone (38 receiving platinum, 6 cetuximab) [81]. The median age of the patients in the CCRT group was somewhat 
higher (61 vs 56 years, $\mathrm{p}=0.02$ ). Disease control and survival outcomes were reported after adjusting for age, T-stage, $\mathrm{N}$-stage and smoking status. A significant difference in distant metastases (adjusted HR 0.32, $\mathrm{p}=0.02$ ) and PFS (adjusted HR $0.46, p=0.03$ ) was observed, while OS showed a trend (adjusted HR 0.48, p = 0.09), all in favor of ICT at 3 years [81]. Finally, also protein expression biomarkers of aggressive disease could be of use in identifying patients who could benefit from ICT [82]. Examples are elevated expression of cyclin D1 and GDF15 expression as predictive markers for benefit of TPF, and acetylated tubulin as a marker for sensitivity to taxane chemotherapy [83-85]. There are also indications that excision repair cross-complementing 1 (ERCC1) expression may be of importance [86, 87]. Bišof et al. [86] reported, based on a meta-analysis of 1288 HNSCC patients who had been treated with platinum-based chemotherapy, that ERCC1 might be a predictive and prognostic factor for individualized therapies for HNSCC patients. In a study of 64 patients with oro- and hypoharyngeal cancers, who received PF induction chemotherapy before definitive local treatment, Hasegawa et al. concluded that ERCC1 was predictive for response to PF and could select those who were candidates for organ preservation [87]. The study included four clinical variables (age, sex, T-class and N-class) and 22 biomarkers which were tested on pretreatment biopsies. In multivariate analysis, next to T-class, ERCC1 expression came forward as the only independent predictive marker for response. The investigators considered that both a DNA repair pathway and an apoptosis pathway are pivotal to the mechanism underlying response to chemotherapy and suggested that further studies on ERCC1 polymorphisms and mutations and assessing apoptotic response associated with p53 activation in HNSCC were needed to clarify genetic associations with response to chemotherapy in HNSCC patients [87].

\section{For Borderline Resectable or Unresectable Oral Cavity Cancer}

Oral cavity cancer is one of the most common malignancies worldwide with geographic variation in incidence and mortality [88]. Higher incidence rates are observed in developing countries compared to developed countries. Bangladesh, Pakistan and India have the highest incidence rates of oral cavity cancer where it is the most common cancer in males and the second in females after breast cancer. As result of delay in presentation, most patients in these countries are diagnosed with advanced disease [89]. Surgery is usually the preferred upfront treatment in patients with oral cavity cancer. However, surgical resection cannot be achieved in many cases with advanced disease without major impact on patient's quality of life. The optimal care of these patients is challenging when surgical treatment is not possible. This is nicely summarized in the recent publication by Alzahrani et al. [89].

The role of induction chemotherapy in patients with resectable oral cavity cancer has been tested in two RTCs and both trials showed a negative outcome [90-92]. Licitra et al. [90] reported on 195 patients with resectable oral cavity cancer (stage 
T2-T4 $(>3 \mathrm{~cm}), \mathrm{N} 0-\mathrm{N} 2, \mathrm{M} 0)$, who were randomized to receive three cycles of PF before surgery versus surgery alone. High-risk patients (positive resection margins, extracapsular nodal spread, nodal disease [N2 or N3], vascular invasion, or perineural invasion) underwent adjuvant RT. There were three toxic deaths in the chemotherapy arm, but ICT did not lead to an improvement in OS (at 5 years $55 \%$ in both arms), locoregional relapse or distant failure. An update of this study with a median follow-up of 11.5 years showed similar results with regard to clinical outcomes [91]. Interestingly, in the late follow-up of the patients in this trial, the control group showed a higher incidence of fibrosis (40\% vs $22 \%$ in chemotherapy arm) and more grade 2 dysphagia ( $14 \%$ versus $5 \%$ in the chemotherapy arm), which the authors ascribed to less extensive surgery carried out in the chemotherapy group (31\% versus $52 \%$ in control group) and less patients receiving postoperative RT (33\% versus $46 \%$ in control group). Zhong et al. [92] randomized 256 patients with stage III or IVA oral squamous cell cancer to receive 2 cycles of TPF followed by surgery and adjuvant RT or surgery and adjuvant RT alone, again showing no difference in survival. A recent meta-analysis of individual patient data of these earlier mentioned two studies confirmed the lack of clinical benefit from ICT [93]. Contrary to that, for $\mathrm{cN} 2$ patients, an OS benefit was found in favor of ICT $(\mathrm{p}=0.04)$. Taken together, it can be concluded that there is no evidence for routine use of ICT in resectable oral cavity cancer.

The main goal of using induction chemotherapy before surgery is to convert borderline resectable disease or clearly unresectable disease to technically resectable disease. Although there are no randomized trials to prove this concept, there are studies, most of them coming from India (not surprising with $64 \%$ of patients have clinical stage IV disease versus $2.2 \%$ in the US), that lead to the same conclusion, i.e. about $30 \%$ will become resectable, and patients in whom this is possible will do better than those in whom this not possible [94-98]. Similar results have been reported by our colleagues in Taiwan [99]. Extension of the tumor to the base of skull, prevertebral muscles and encasement or invasion of the carotid artery are absolute contraindication to surgery. In addition, Patil et al. [96] adopted criteria specifically for oral cavity cancer. These include: (1) buccal mucosa primary with diffuse margins and peritumoral edema, going up to or above the level of zygomatic arch and without any satellite nodules, (2) tongue primary (anterior two-thirds) with the tumor extending up to or below the level of the hyoid bone, (3) extension of tumor of anterior two-thirds of the oral tongue to the vallecula, (4) extension of tumor into the high infratemporal fossa, as defined by extension of tumor above an axial plane passing at the level of the sigmoid notch, and (5) extensive skin infiltration impacting the achievement of negative margin. The Indian studies mentioned above are summarized in Table 11.7. Febrile neutropenia in some of these studies was reported to be a major problem. Nevertheless, according to in particular our Indian colleagues, who see these far advanced stages of disease much more frequently than we do in the higher income countries, ICT may be considered in patients with unresectable or borderline resectable oral cavity cancers, as it may increase the chance of resectability and subsequently might improve outcomes. 
Table 11.7 Induction chemotherapy in unresectable/borderline resectable locally advanced OSCC*

\begin{tabular}{l|l|l|l|l}
\hline Investigators & $\begin{array}{l}\text { No.of } \\
\text { pts }\end{array}$ & $\begin{array}{l}\text { Disease } \\
\text { stage (T) }\end{array}$ & Treatments & Outcomes \\
\hline $\begin{array}{l}\text { Rudresha } \\
\text { et al. [94] }\end{array}$ & 116 & IV (T4b) & $\begin{array}{l}\text { TPF or TP } \\
(2-3 \mathrm{x}) \rightarrow \mathrm{S}\end{array}$ & $\begin{array}{l}\text { Resect. 19\%; mOS 19.7 mo; mOS with } \\
\text { NST 7.1 mo }\end{array}$ \\
\hline $\begin{array}{l}\text { Joshi et al. } \\
{[95]}\end{array}$ & 110 & IV (T4b) & $\begin{array}{l}\text { TPF or TP } \\
(2-3) \rightarrow \mathrm{S}\end{array}$ & $\begin{array}{l}\text { Resect. 30.9\%; mOS 18.0 mo; mOS with } \\
\text { NST 6.5 mo }\end{array}$ \\
\hline $\begin{array}{l}\text { Patil et al. } \\
{[96]}\end{array}$ & 721 & $\begin{array}{l}\text { IV (T4a/ } \\
\text { T4b) }\end{array}$ & $\begin{array}{l}\text { TP or TPF } \\
(2 \mathrm{x}) \rightarrow \mathrm{S}\end{array}$ & $\begin{array}{l}\text { Resect. 43\%; mOS 19.6 mo; mOS with } \\
\text { NST 8.16 mo; 24 mo LRCT rate 32\% vs } \\
15 \%\end{array}$ \\
\hline $\begin{array}{l}\text { Rudresha } \\
\text { et al. [97] }\end{array}$ & 80 & IV (T4a) & TP $(2-3) \rightarrow \mathrm{S}$ & $\begin{array}{l}\text { Resect. 23.8\%; mOS 16.9 mo; mOS with } \\
\text { NST 8.8 mo }\end{array}$ \\
\hline
\end{tabular}

OSCC oral squamous cell carcinoma, TPF docetaxel/cisplatin/5-FU, TP taxane/platinum, $m O S$ median overall survival, NST nonsurgical treatment, LRCT locoregional control, Resect. resectable, *Patil's criteria

\section{As a Selection Tool for RT Dose de-Escalation in HPV-Positive OPSCC}

Treatment of patients with HPV-positive OPSCC is rapidly evolving and challenging the standard of care of definitive RT with concurrent cisplatin [100]. Several de-escalation approaches are under study, among which are radiation alone instead of radiation combined with cisplatin, radiation combined with cetuximab instead of radiation combined with cisplatin, transoral surgery followed or not by postoperative RT and ICT followed by decreased radiation dose and/or volumes for good responders. In the latter setting, ICT is used as a tool to stratify patients by treatment response. De-escalation approaches are getting major attention in patients with locoregionally advanced OPSCC, because these patients have overall a better prognosis and if treated curatively with current standard treatment (CCRT), are confronted with possible long-term toxicity issues, such as feeding tube dependency $\geq 2$ years post RT, pharyngeal dysfunction (dysphagia), laryngeal dysfunction, mucositis, or other toxicities (e.g. infection, fistula, weight loss etc). Three US trials have reported on ICT approaches, i.e. ECOG 1308 (NCT 01084083), the Quarterback trial (NCT 01706939) and the OPTIMA HPV trial (NCT 02258659).

ECOG 1308 was a single arm phase II study in which patients with HPVassociated OPSCC (the majority having T1-3N0-N2b disease and a history of $\leq 10$ pack-years of smoking) were treated with three cycles paclitaxel, cisplatin and cetuximab, followed by cetuximab concurrently with intensity-modulated radiation therapy (IMRT). The purpose of the study was to evaluate whether a clinical CR to ICT could select patients for reduced radiation dose as a means of sparing late sequelae [101]. Patients with CR at the primary received a reduced RT dose (54 Gy instead of $69.3 \mathrm{~Gy}$ ). Involved lymph nodes received $69.3 \mathrm{~Gy}$ unless they also were judged to have completely responded. The primary end point was 2-year PFS. Of the 90 patients enrolled, 80 were evaluable and 77 received three cycles of ICT. Fiftysix patients (70\%) had a CR to the İCT at the primary site and 51 patients continued 
to cetuximab with IMRT $54 \mathrm{~Gy}$. At a median follow-up of 35.4 months, the 2-year PFS and OS rates were $80 \%$ and $94 \%$ among those 51 patients. These figures were most promising (96\% and $96 \%$, respectively) for the more favorable group of patients (i.e. having $<\mathrm{T} 4,<\mathrm{N} 2 \mathrm{c}$ and $\leq 10$ pack-years of smoking). At 12 months, significantly fewer patients treated with the reduced RT dose had difficulty swallowing solids (40\% v 89\%; P =.011) or had impaired nutrition $(10 \% \mathrm{v} 44 \%$; $\mathrm{P}=.025)$. The authors concluded that a reduced-dose IMRT with concurrent cetuximab was worthy of further study in favorable-risk patients with HPVassociated OPSCC.

The Quarterback trial, a phase III trial in patients with locally advanced p16positive OPSCC and $\leq 20$ pack years smoking, made use of three cycles of the American TPF regimen and clinical responders who were HPV-positive by typespecific PCR were randomized 1:2 to standard-dosed (sd) IMRT (70 Gy) or reduceddosed (rd) IMRT (54 Gy), both combined with weekly carboplatin at AUC 1.5. The endpoints of the study were 3-year PFS and OS. The planned number of patients was 365 with 240 in the experimental arm. The original statistical plan was revised because of poor accrual. The trial terminated after 20 evaluable patients were randomized and treated ( 8 with sdCCRT and 12 rdCCRT). Sixteen (80\%) were HPV16positive and $4(20 \%)$ had other high-risk (HR) variants. Fourteen $(70 \%)$ had high risk features: T4, N2c, or N3. Median follow up was 56 months (range 42-70). Three-year PFS/OS for sdCCRT and rdCCRT were $87.5 \%$ vs $83.3 \%$ (log-rank test, $\mathrm{p}=0.85)$, respectively. All three failures were locoregional within 4 months of completion of CCRT, 2 were in HR variants. As mentioned by the authors, the small sample size limits the interpretation of the outcome, but the study supports the potential clinical benefit of radiation dose reduction after ICT as a treatment strategy [102].

In the OPTIMA HPV trial, patients were classified as low-risk (LR) $(\leq \mathrm{T} 3$, $\leq \mathrm{N} 2 \mathrm{~B}, \leq 10$ pack year history) or high-risk (HR) (T4, $\geq \mathrm{N} 2 \mathrm{c},>10$ pack year history). Patients received ICT of three cycles of dose dense carboplatin and nab-paclitaxel. LR patients with 50\% response received 50 Gray (Gy) RT (RT50) while LR patients with 30\%-50\% response or HR patients with 50\% response received 45 Gy CCRT (CCRT45). Patients with lesser response received standard-of-care 75 Gy CCRT (CCRT75). The primary end point was 2-year progression-free survival compared with a historical control of $85 \%$. Secondary end points included overall survival and toxicity. Sixty-two patients (28 LR/34 HR) were enrolled [103]. Of the LR patients, $71 \%$ received RT50 while $21 \%$ received CRT45. Of the HR patients, $71 \%$ received CRT45. With a median follow-up of 29 months, 2-year PFS and OS were $95 \%$ and $100 \%$ for LR patients and $94 \%$ and $97 \%$ for HR patients, respectively. The overall 2-year PFS was $94.5 \%$ and within the $11 \%$ non-inferiority margin for the historical control. Grade $\geq 3$ mucositis occurred in $30 \%, 63 \%$, and $91 \%$ of the RT50, CCRT45, and CCRT75 groups, respectively $(\mathrm{P}=0.004)$. Rates of any PEG-tube use were $0 \%$, $31 \%$, and $82 \%$ for RT50, CCRT45, and CCRT75 groups, respectively $(\mathrm{P}<0.0001)$ [103]. This decreased over time, being at 12 months $0 \%, 4 \%$ and $9 \%$, respectively. Updated information was presented at ASCO 2020, now including 107 patients that were treated according to the same lines and now with a median follow-up of 
36 months [104]. Overall, 94\% of patients were alive at last follow-up (98\% LR; $89 \%$ HR). Three patients developed a recurrence (2 HR and 1 LR); 2 local and 1 at distance. This OPTIMA approach demonstrated excellent oncologic and functional outcomes with long-term follow-up.

Despite these promising results, clinicians should refrain from de-escalation approaches outside clinical trials for this moment, because the safety of these approaches are still unclear. This has been reinforced by unexpected negative outcomes of two RCTs, in which cetuximab plus RT was compared with the standard-of-care cisplatin-based CCRT in p16-positive OPSCC [105, 106].

\section{Oligometastatic Disease}

Another area of potential interest for the applicability of induction chemotherapy is oligometastatic disease. It is estimated that 5-47\% (mean 15\%) of patients will have distant metastases during the course of the disease [107]. The Surveillance Epidemiology and End Results (SEER) database revealed that $19 \%$ of patients with oral cavity or pharynx cancer presented with distant metastases at diagnosis [108]. The most common site of metastases from HNSCC is the lung accounting for up to $70 \%$ to $85 \%$, followed by metastases to the bone (up to $20 \%$ ) and liver (up to $10 \%$ ). Other organs such as the brain, mediastinum, skin and bone marrow occur even more rarely [109]. There are different definitions of oligometastases for different cancers, but a consensus definition is five or fewer sites of metastatic disease [109]. Patients with oligometastatic HNSCC can be divided in two groups; (1) those who present with metastatic disease at initial diagnosis, i.e. synchronous distant metastases, and (2) those who have developed the metastatic lesions during their surveillance after their definitve treatment, the so-called metachronous distant metastases, with or without locoregional disease relapse.

Considering all patients with metastatic HNSCC as one group that should be treated with systemic therapy for palliation might not be correct. The contemporary standard of care systemic therapies result in a median survival of 10.1 to 13.6 months and it is unclear yet whether the treatment with immune checkpoint inhibitors will lead to cure $[40,110]$. However, metastatic disease in HNSCC covers a wide range of disease presentations, depending not only on the site from which these metastases are originating, but also on the tumor biology and kinetics, whereby metastatic disease may vary from widely disseminated disease to oligometastatic disease.

Oligometastatic disease is a moving concept not only defined by its phenotypic metastatic burden but also by the ability to perform metastatic-directed treatments [107]. Advances in minimally invasive surgery and whole body stereotactic hypofractionated radiation therapy have opened an avenue to treat metastases in a safe, well-tolerated and relatively cost-effective manner. In a retrospective series from Germany, the authors noted a significant survival benefit for HNSCC patients who 
received a specific therapy regarding distant metastases irrespective of localization as compaired to a matched control cohort [111]. An analysis of patients with metastatic HNSCC in the National Cancer Database (NCDB) revealed that the patients who received high-intensity local treatment (defined as radiation doses $\geq 60$ Gy or oncologic resection of the primary tumor) and systemic therapy had a $13 \%$ improvement in 2-year overall survival(OS) compared to patients receiving systemic therapy alone [112]. It is beyond the scope of this chapter on induction chemotherapy to discuss extensively the treatment of oligometastatic disease and the participation of local therapies therein. Suffice to say that currently, due to the lack of randomized but also sufficiently powered prospective trials, no firm recommendations can be given on how to optimally treat oligometastatic disease. However, ablative techniques have already penetrated into routine clinical practices in high-volume centers [113].

The role of induction chemotherapy in this context is primarily concerning synchronous metastatic disease at first diagnosis. Singular cases can be found in the literature were upfront chemotherapy is given with curative intent. Therefore strategies combining induction chemotherapy and upfront metastasis-directed treatments prior to locoregional therapy for the primary tumor can be anticipated [82].

\section{Where to Use Induction Chemotherapy}

Toxicity is an issue of ICT, in particular when there is not much experience with the contemporary ICT regimens. With the European TPF regimen, as given in TAX 323/EORTC 24971 [44], i.e. with prophylactic antibiotics [ciprofloxacin from day 5-15] in each cycle and dexamethasone given before the start of each cycle to prevent docetaxel-related hypersensitivity reactions, skin toxicity and fluid retention, common ( $\geq 5 \%$ ) grade 3-4 adverse events included: neutropenia (76.9\%), leukopenia $(41.6 \%)$, alopecia $(11.6 \%)$, anemia $(9.2 \%)$, infection $(6.9 \%)$, febrile neutropenia $(5.2 \%)$ and thrombocytopenia $(5.2 \%) .6 .2 \%$ of patients discontinued treatment due to adverse events and there were $2.3 \%$ toxic deaths. With the American TPF, as given in TAX 324 [43], premedication, prophylactic antibiotics and dexamethasone were given in the manner as in TAX 323/EORTC 24971, common ( $\geq 5 \%)$ grade 3-4 adverse events included: neutropenia (83\%), stomatitis/mucositis $(21 \%)$, nausea (14\%), dysphagia (13\%), anemia/febrile neutropenia/neutropenia infection/anorexia (each $12 \%$ ), vomiting (8\%), diarrhea (7\%), infection (6\%), and lethargy [5]. 6\% of patients discontinued treatment due to adverse events related to treatment and there $<1 \%$ deaths due to toxic effect of study medication.

Crucially in the safe use of TPF regimens is that it is being administered by experienced oncologists, familiar with the necessary protocols and supportive care requirements to ensure patient safety and maximize adherence throughout the treatment [114]. Adequate fluid management, especially on days 1-2 during TPF 
administration is crucial in preventing renal toxicity, hypovolemia, and severe fatigue. Discussing the patient in multidisciplinary team (MDT) meetings is strongly advised, considering also additional matters such as patient's psychological and nutritional status, potential for palliative care, addiction services, and speech therapy. The importance of MDT meetings have been extensively discussed during THNO-5 [115]. MDT meetings have emerged as a practical necessity for optimal coordination among health professionals and clear communication with patients, and increasingly more attention is paid to psychological aspects, quality of life, patient's rights and empowerment, and survivorship. Moreover, it has become more and more clear that treatment in higher volume centers, and experience of the center in trial participation correlate with outcomes [116, 117].

\section{Conclusions}

For more than 10 years the PF regimen has been replaced by the TPF regimen as the standard ICT regimen [43, 44]. ICT has an established role for organ preservation in advanced laryngeal and hypopharyngeal cancer and the TPF regimen has been validated in that setting. There remains uncertainty about the benefit of the sequential approach of ICT followed by CCRT, despite the fact that ICT significantly reduces the occurrence of distant metastases. It seems therefore appropriate to further study ICT in patients who have the highest risk to develop distant metastases, in particular patients with low neck nodes and matted nodes. Moreover, further studies in patients with HPV-associated OPSCC at risk for distant failure (T4 or N3 disease) could be considered for that also. Retrospective data from India suggest that ICT may play an important role in converting borderline resectable disease or clearly unresectable disease to technically resectable disease. Therefore, larger randomized trials in patients with borderline resectable cancer of the oral cavity are needed to establish the benefit of induction chemotherapy in this setting. Data are available that suggest that ICT can be used as a tool to select HPV-associated OPSCC patients for dose and volume de-escalation of RT, and retaining excellent oncologic and functional outcomes. These approaches still need to be confirmed in adequately sized clinical trials. Outside clinical trials, the utility of ICT is restricted to uniquely pragmatic clinical scenarios, such as unavoidable delay in radiation or in the situation that RT is not tolerated or feasible. This can happen when there is severe pain from advanced disease or there is impending airway compromise or neurologic dysfunction that necessitates rapid initiation of treatment [82]. Future areas of research are the role of ICT in strategies whereby ICT is combined with upfront metastases-directed treatments, the usefulness of targeted agents or immune checkpoint inhibitors in the induction setting; studies in that direction have started. Finally, the application of radiographic, proteomic and genomic biomarkers will get attention to further define prognostic groups and guide treatment selection with greater precision. 


\section{References}

1. Bray F, Ferlay J, Soerjomataram I, Siegel RL, Torre LA, Jemal A. Global cancerstatistics 2018: GLOBOCAN estimates of incidence and mortality worldwide for 36 cancers in 185 countries. CA Cancer J Clin. 2018;68:394-424.

2. Omran AR. The epidemiologic transition. A theory of the epidemiology of population change. Milbank Mem Fund Q. 1971;49:509-38.

3. Gersten O, Wilmoth JR. The cancer transition in Japan since 1951. Demogr Res. 2002;7:271-306.

4. Marur S, Forastiere AA. Head and neck cancer: changing epidemiology, diagnosis, and treatment [published correction appears in Mayo Clin Proc 2008;83(5):604]. Mayo Clin Proc. 2008;83:489-501.

5. Marur S, Forastiere AA. Head and neck squamous cell carcinoma: update on epidemiology, diagnosis, and treatment. Mayo Clin Proc. 2016;91:386-96.

6. Sturgis EM, Cinciripini PM. Trends in head and neck cancer incidence in relation to smoking prevalence: an emerging epidemic of human papillomavirus-associated cancers? Cancer. 2007;110:1429-35.

7. Gillison ML, Broutian T, Pickard RK, et al. Prevalence of oral HPV infection in the United States, 2009-2010. JAMA. 2012;307:693-703.

8. Steinberg BM, DiLorenzo TD. A possible role for human papillomavirus in head and neck cancer. Cancer Metastases Rev. 1996;15:91-112.

9. Gillison ML, et al. Evidence for a causal association between papillomavirus and a subset of head and neck cancers. J Natl Cancer Inst. 2000;92:709-20.

10. Mehanna H, Beech T, Nicholso T, et al. Prevalence of human papillomavirus in oropharyngeal and nonoropharyngeal head and neck cancer-systematic review and meta-analysis of trends by time and region. Head Neck. 2013;35:747-55.

11. Chaturvedi AK, Engels EA, Anderson WF, Gillison ML. Incidnece trends for human papillomavirus-related and-unrelated oral squamous cell carcinoma in the United States. J Clin Oncol. 2008;26:612-9.

12. Rischin D, Young RJ, Fox SR, et al. Prognostic significance of p16INK4A and human papillomavirus in patients with oropharyngeal cancer treated on TROG 02.02 phase III trial. J Clin Oncol. 2010;28:4142-8.

13. Gillison ML, D'Souza G, Westra W, et al. Distinct risk factor profiles for human papillomavirus type 16-positive and human papillomavirus type 16-negative head and neck cancers. J Natl Cancer Inst. 2008;100:407-20.

14. Rettig EM, Zaidi M, Faraji F, et al. Oropharyngeal cancer is no longer a disease of younger patients and the prognositc advantage of human papillomavirus is attenuated among older patients: analysis of the national cancer database. Oral Oncol. 2018;83:147-53.

15. Zumsteg ZS, Cook-Wiens G, Yoshida E, et al. Incidence of oropharyngeal cancer among elderly patients in the United States. JAMA Oncol. 2016;2:1617-23.

16. Windon MJ, D'Souza G, Rettig EM, et al. Increasing prevalence of human papillomaviruspositive oropharyngeal cancers among older adults. Cancer. 2018;124:2993-9.

17. Al-Sarraf M. Treatment of locally advanced head and neck cancer: historical and critical review. Cancer Control. 2002;9:387-99.

18. Al-Sarraf M. Chemotherapy strategies in squamous cell cancer of the head and neck. CRC Crit Rev Oncol/Hematol. 1984;1:323-55.

19. Choski AJ, Dimery IW, Hong WK. Adjuvant chemotherapy of head and neck cancer: the past, the present, and the future. Semin Oncol. 1988;15(suppl 3):45-59.

20. Kish JA, Drelichman A, Jacobs J, et al. Clinical trial of cisplatin and 5-fluorouracil as initial therapy for advanced squamous cell carcinoma of the head and neck. Cancer Treat Rep. 1982;66:471-4. 
21. Decker DA, Drelichman A, Jabobs J, et al. Adjuvant chemotherapy with cisdiamminedichloroplatinum (II) and 12o hour infusion in stage III and IV squamous cell carcinoma of the head and neck. Cancer. 1983;51:1353-5.

22. Jacobs JR, Pajak TF, Kinzie J, et al. Induction chemotherapy in advanced head and neck cancer. Arch Otolaryngol Head Neck Surg. 1987;113:193-7.

23. Kish JA, Ensley JF, Jacobs JR, Binns P, Al-Sarraf M. Evaluation of high-dose cisplatin and 5-FU infusion as initial therapy in advanced head and neck cancer. Am J Clin Oncol. 1988;11:553-7.

24. Snow GB, Vermorken JB. Neo-adjuvant chemotherapy in head and neck cancer: state of the art, 1988. Clin Otolaryngol. 1989;14:371-5.

25. Ensley JF, Jacobs JR, Weaver A, et al. Correlation between response to cisplatinum combination chemotherapy and subsequent radiotherapy in previously untreated patients with advanced squamous cell cancers of the head and neck. Cancer. 1984;54:811-4.

26. Al-Sarraf M. Head and neck cancer: present status and future prospects of adjuvant chemotherapy. Cancer Investig. 1995;13:41-53.

27. Pignon JP, Bourhis J, Domenge C, Designe L. Chemotherapy added to locoregional treatment for head and neck carcinoma: three meta-analyses of updated individual data MACH-NC collaborative group. Meta-analysis of chemotherapy on head and neck cancer. Lancet. 2000;355:949-55.

28. Monnerat C, Faivre S, Temam S, Bourhis J, Raymond E. End points for new agents in induction chemotherapy for locally advanced head and neck cancers. Ann Oncol. 2002;13:995-1006.

29. Adelstein DJ, Li Y, Adams GL, Wagner H, Kish JA, Ensley JF, et al. An intergroup phase III comparison of standard radiation therapy and two schedules of concurrent chemoradiotherapy in patients with unresectable squamous cell head and neck cancer. J Clin Oncol. 2003;21:92-8.

30. Forastiere AA, Goepfert H, Maor M, Pajak TF, Weber R, Morrison W, et al. Concurrent chemotherapy and radiotherapy for organ preservation in advanced laryngeal cancer. N Engl $\mathrm{J}$ Med. 2003;349:2091-8.

31. Bernier J, Domenge C, Ozsahin M, Matuszewska K, Lefèbvre JL, Greiner RH, et al. Postoperative irradiation with or without concomitant chemotherapy or locally advanced head and neck cancer. N Engl JMed. 2004;350:1945-52.

32. Cooper JS, Pajak TF, Forastiere AA, Jacobs J, Campbell BH, Saxman SB, et al. Postoperative concurrent radiotherapy and chemotherapy for high-risk squamous-cell carcinoma of the head and neck. N Engl J Med. 2004;350:1937-44.

33. Schmitz S, Ang KK, Vermorken J, et al. Targeted therapies for squamous cell carcinoma of the head and neck: current knowledge and future directions. Cancer Treat Rev. 2014;40:390-404.

34. Vermorken JB, Mesia R, Rivera F, et al. Platinum-based chemotherapy plus cetuximab in head and neck cancer. N Engl J Med. 2008;359:1116-27.

35. Bonner JA, Harari PM, Giralt J, et al. Radiotherapy plus cetuximab for squamous-cell carcinoma of the head and neck. N Engl J Med. 2006;354:567-78.

36. Bonner JA, Harari PM, Giralt J, et al. Radiotherapy plus cetuximab for locoregionally advanced head and neck cancer: 5-year survival data from a phase 3 randomised trial, and relation between cetuximab-induced rash and survival. Lancet Oncol. $2010 \mathrm{Jan} ; 11: 21-8$.

37. Santuray RT, Johnson DE, Grandis. New therapies in head and neck cancer. Trends Cancer. 2018;4:385-96.

38. Ferris RL, Blumenschein G, Fayette J, et al. Nivolumab for recurrent squamous-cell carcinoma of the head and neck. N Engl J Med. 2016;375:1856-67.

39. Cohen EEW, Soulières D, Le Tourneau C, et al. Pembrolizumab versus methotrexate, docetaxel, or cetuximab for recurrent or metastatic head-and-neck squamous cell carcinoma (KEYNOTE-040): a randomised, open-label, phase 3 study. Lancet. 2019;393:156-67.

40. Burtness B, Harrington KJ, Greil R, et al. Pembrolizumab alone or with chemotherapy versus cetuximab with chemotherapy for recurrent or metastatic squamous cell carcinoma of the head and neck (KEYNOTE-048): a randomised, open-label, phase 3 study. Lancet. 2019;394:1915-28. 
41. Schrijvers D, Vermorken JB. Role of toxoids in head and neck cancer. Oncologist. 2000;5:199-208.

42. Schrijvers D, Vermorken JB. Taxanes in the treatment of head and neck cancer. Curr Opin Oncol. 2005;17:218-24.

43. Posner MR, Hershock DM, Blajman CR, et al. Cisplatin and fluorouracil alone or with docetaxel in head and neck cancer. N Engl J Med. 2007;357:1705-15.

44. Vermorken JB, Remenar E, van Herpen C, et al. Cisplatin, fluorouracil, and docetaxel in unresectable head and neck cancer. N Engl J Med. 2007;357:1695-704.

45. van Herpen CM, Mauer ME, Mesia R, et al. Short-term health-related quality of life and symptom control with docetaxel, cisplatin, 5-fluorouracil and cisplatin (TPF), 5-fluorouracil (PF) for induction in unresectable locoregionally advanced head and neck cancer patients (EORTC 24971/TAX 323). Br J Cancer. 2010;103:1173-81.

46. Liberato NL, Rognoni C, Rubrichi S, et al. Adding docetaxel to cisplatin and fluorouracil in patients with unresectable head and neck cancer: a cost-utility analysis. Ann Oncol. 2012;23:1825-32.

47. Blanchard P, Bourhis J, Lacas B, et al. Taxane-cisplatin-fluorouracil as induction chemotherapy in locally advanced head and neck cancers: an individual patient data meta-analysis of the meta-analysis of chemotherapy in head and neck cancer group. J Clin Oncol. 2013;31:2854-60.

48. Hitt R, Lopez-Pousa A, Martinez-Trufero J, et al. Phase III study comparing cisplatin plus fluorouracil to paclitaxel, cisplatin, and fluorouracil induction chemotherapy followed by chemoradiotherapy in locally advanced head and neck cancer. J Clin Oncol. 2005;23:8636-45.

49. Hitt R, Grau JJ, Lopez-Pousa A, et al. A randomized phase III trial comparing induction chemotherapy followed by chemoradiotherapy versus chemoradiotherapy alone as treatment of unresectable head and neck cancer. Ann Oncol. 2014;25:216-25.

50. Forastiere AA, Adelstein DJ, Manola J. Induction chemotherapy metaanalysis in head and neck cancer: right answer, wrong question. J Clin Oncol. 2013;31:2844-6.

51. Domenge C, Hill C, Lefebvre JL, et al. Randomized trial of neoadjuvant chemotherapy in oropharyngeal carcinoma. French Groupe d'Etude des Tumeurs de la Tete et du Cou (GETTEC). Br J Cancer. 2000;83:1594-8.

52. Paccagnella A, Orlando A, Marchiori C, et al. Phase III trial of initial chemotherapy in stage III or IV head and neck cancers: a study by the Gruppo di studio sui Tumori della Testa e del Collo. J Natl Cancer Inst. 1994;86:265-72.

53. Hitt R, Grau JJ, Lopez-Pousa A, et al. A randomized phase III trial comparing induction chemotherapy followed by chemoradiotherapy versus chemoradiotherapy alone as treatment of unresectable head and neck cancer. Ann Oncol. 2014;25:216-25.

54. Haddad R, O'Neill A, Rabinowits G, et al. Induction chemotherapy followed by concurrent chemoradiotherapy (sequential chemoradiotherapy) versus concurrent chemoradiotherapy alone in locally advanced head and neck cancer (PARADIGM): a randomised phase 3 trial. Lancet Oncol. 2013;14:257-64.

55. Cohen EE, Karrison TG, Kocherginsky M, et al. Phase III randomized trial of induction chemotherapy in patients with $\mathrm{N} 2$ or N3 locally advanced head and neck cancer. J Clin Oncol. 2014;32:2735-43.

56. Ghi MG, Paccagnella A, Ferrari D, et al. Induction TPF followed by concomitant treatment versus concomitant treatment alone in locally advanced head and neck cancer. A phase II-III trial. Ann Oncol. 2017;28:2206-12.

57. Geoffrois L, Martin L, De Raucourt D, Sun XS, Tao Y, Maingon P, et al. Induction chemotherapy followed by cetuximab radiotherapy is not superior to concurrent chemoradiotherapy for head and neck carcinomas: results of the GORTEC 2007-02 phase III randomized trial. J Clin Oncol. 2018;36:3077-83.

58. González Ferreira JA, Olasolob JJ, Azinovic I, Jeremic B. Effect of radiotherapy delay in overall treatment time on local control and survival in head and neck cancer: review of the literature. Rep Pract Oncol Radiother. 2015;20:328-39. 
59. Fayette J, Fontaine-Delaruelle C, Ambrun A, et al. Neoadjuvant modified TPF (docetaxel, cisplatin, fluorouracil) for patients unfit to standard TPF in locally advanced head and neck squamous cell carcinoma: a study of 48 patients. Oncotarget. 2016;7:37297-304.

60. Herman LC, Chen L, Garnett A, et al. Comparison of carboplatin-paclitaxel to docetaxelcisplatin-5-fluorouracil induction chemotherapy followed by concurrent chemoradiation for locally advanced head and neck cancer. Oral Oncol. 2014;50:52-8.

61. Zenda S, Ota Y, Kiyota N, et al. A multicenter phase II trial of docetaxel, cisplatin, and cetuximab (TPEx) followed by cetuximab and concurrent radiotherapy for patients with local advanced squamous cell carcinoma of the head and neck (CSPOR HN01: ECRIPS study). Front. Oncologia. 2019;9:6.

62. Ferrari D, Ghi M, Franzese C, Codecà C, Gau M, Fayette J. The slippery role of induction chemotherapy in head and neck cancer: myth and reality. Front Oncol. 2020;10:7.

63. The Department of Veterans Affairs Laryngeal Cancer Study Group. Induction chemotherapy plus radiation compared with surgery plus radiation in patients with advanced laryngeal cancer. N Engl J Med. 1991;324:1685-90.

64. Lefebvre JL, Chevalier D, Luboinski B, et al. Larynx preservation in pyriform sinus cancer: preliminary results of the European organization for research and treatment of cancer phase III trial. EORTC head and neck cooperative group. J Natl Cancer Inst. 1996;88:890-9.

65. Lefebvre JL, Andry G, Chevalier D, et al. Laryngeal preservation with induction chemotherapy for hypopharyngeal squamous cell carcinoma: 10-year results of EORTC trial 24891. Ann Oncol. 2012;23:2708-14.

66. Lefebvre JL. What is the optimal larynx preservation approach and who are the candidates? In: Vermorken JB, Budach V, Leemans CR, Machiels JP, Nicolai P, O'Sullivan B, editors. Critical issues in head and neck oncology. Springer nature Switzerland AG; 2018. p. 215-25.

67. Lefebvre JL, Ang KK. Larynx preservation clinical trial design: key issues and recommendations- a consensus panel summary. Int J Radiat Oncol Biol Phys. 2009;73:1293-303.

68. Lefebvre JL, Rolland F, Tesselaar M, et al. Phase 3 randomized trial on larynx preservation comparing sequential vs alternating chemotherapy and radiotherapy. J Natl Cancer Inst. 2009;101:142-52.

69. Henriques de Figueiredo B, Fortpied C, Menis J, et al. Long-term update of the 24954 EORTC phase III trial on larynx preservation. Eur J Cancer. 2016;65:109-12.

70. Forastiere AA, Goepfert H, Maor M, et al. Concurrent chemotherapy and radiotherapy for organ preservation in advanced laryngeal cancer. N Engl J Med. 2003;349:2091-8.

71. Forastiere AA, Zhang Q, Weber RS, et al. Long-term results of RTOG 91-11: a comparison of three nonsurgical strategies to preserve the larynx in patients with locally advanced larynx cancer. J Clin Oncol. 2013;31:845-52.

72. Pointreau Y, Garaud P, Chapet S, et al. Randomized trial of induction chemotherapy with cisplatin and 5-fluorouracil with or without docetaxel for larynx preservation. J Natl Cancer Inst. 2009;101:498-506.

73. Janoray G, Pointreau Y, Garaud P, et al. Long-term results of a multicenter randomized phase III trial of induction chemotherapy with cisplatin, 5-fluorouracil, \pm docetaxel for larynx preservation. J Natl Cancer Inst. 2015;108:djv368.

74. Posner MR, Norris CM, Wirt LJ, et al. Sequential therapy for the locally advanced larynx and hypopharynx cancer subgroup in TAX 324: survival, surgery, and organ preservation. Ann Oncol. 2009;20:921-7.

75. Pignon JP, le Maitre A, Maillard E, Bourhis J on behalf of the MACH-NC Collaborative Group. Meta-analysis of chemotherapy in head and neck cancer (MACH-NC): an update on 93 randomised trials and 17,346 patients. Radiother Oncol. 2009;92:4-14.

76. Ma J, Liu Y, Huang XL, et al. Induction chemotherapy decreases the rate of distant metastasis in patients with head and neck squamous cell carcinoma but does not improve survival or locoregional control: a meta-analysis. Oral Oncol. 2012;48:1076-84.

77. Zhang L, Jiang N, Shi Y, Li S, Wang P, Zhao Y. Induction chemotherapy with concurrent chemoradiotherapy versus concurrent chemoradiotherapy for locally advanced squamous cell carcinoma of head and neck: a meta-analysis. Sci Rep. 2015;5:10798. 
78. Iocca O, Farcomeni A, Di Rocco A, et al. Locally advanced squamous cell carcinoma of the head and neck: a systematic review and Bayesian network meta-analysis of the currently available treatment options. Oral Oncol. 2018;80:40-51.

79. Kim DH, Kim WT, Lee JH, et al. Analysis of the prognostic factors for distant metastasis after induction chemotherapy followed by concurrent chemoradiotherapy for head and neck cancer. Cancer Res Treat. 2015;47:46-54.

80. O'Sullivan B, Huang SH, Siu LL, et al. Deintensification candidate subgroups in human papillomavirus-related oropharyngeal cancer according to minimal risk of distant metastasis. J Clin Oncol. 2013;31:543-50.

81. Bhattasali O, Han J, Thompson LDR, Buchschacher GL Jr, Abdallad IA, Iganej S. Induction chemotherapy followed by concurrent chemoradiation versus concurrent chemoradiation alone in the definitive management of p16-positive oropharyngeal squamous cell carcinoma with low-neck or N3 disease. Oral Oncol. 2018;78:151-5.

82. Chapman CH, Parvathaneni U, Yom SS. Revisiting induction chemotherapy before radiotherapy for head and neck cancer, part I: carcinoma of non-nasopharyngeal sites. Future Oncol. 2017:13:469-75.

83. Zhong LP, Zhu DW, William W, et al. Elevated cyclin D1 expression is predictive for a benefit from TPF induction chemotherapy in oral squamous cell carcinoma patients with advanced nodal disease. Mol Cancer Ther. 2013;12:1112-21.

84. Yang CZ, Ma J, Zhu DW, et al. GDF15 is a potential predictive biomarker for TPF induction chemotherapy and promotes tumorigenesis and progression in oral squamous cell carcinoma. Ann Oncol. 2014;25:1215-22.

85. Saba NF, Magliocca KR, Kim S, et al. Acetylated tubulin (AT) as a prognostic marker in squamous cell carcinoma of the head and neck. Head and Neck Pathol. 2014;8:66-72.

86. Bišof V, Zajc Petranović M, Rakušić Z, Samardžić KR, Juretić A. The prognostic and predictive value of excision repair cross-complementation group 1 (ERCC1) protein in 1288 patients with head and neck squamous cell carcinoma treated with platinum-based therapy: a metaanalysis. Eur Arch Otorhinolaryngol. 2016;273:2305-17.

87. Hasegawa Y, Goto M, Hanai N, Ozawa T, Hirakawa H. Predictive biomarkers for combined chemotherapy with 5-fluorouracil and cisplatin in oro- and hypopharyngeal cancers. Mol Clin Oncol. 2018;8:378-86.

88. Fitzmaurice C, Allen C, Barber RM, et al. Global, regional, and national cancer incidence, mortality, years of life lost, years lived with disability, and disability-adjusted life-years for 32 cancer groups, 1990 to 2015: a systematic analysis for the global burden of disease study global burden. JAMA Oncol. 2017;3:524-48.

89. Alzahrani R, Obaid A, Al-Hakami H. Locally advanced oral cavity cancers: what is the optimal care? Cancer Control. 2020;27:1-11.

90. Licitra L, Grandi C, Guzzo M, et al. Primary chemotherapy in resectable oral cavity squamous cell cancer: a randomized controlled trial. J Clin Oncol. 2003;21:327-33.

91. Bossi P, Lo Vullo S, Guzzo M, et al. Preoperative chemotherapy in advanced resectable OCSCC: long-term results of a randomized phase III trial. Ann Oncol. 2014;25:462-6.

92. Zhong L, Zhang C, Ren G, et al. Randomized phase III trial of induction chemotherapy with docetaxel, cisplatin, and fluorouracil followed by surgery versus up-front surgery in locally advanced resectable oral squamous cell carcinoma. J Clin Oncol. 2013;31:744-51.

93. Marta GN, Riera R, Bossi P, et al. Induction chemotherapy prior to surgery with or without postoperative radiotherapy for oral cavity cancer patients: systematic review and metaanalysis. Eur J Cancer. 2015;51:2596-603.

94. Rudresha A, Chaudhuri T, Lakshmaiah K, et al. Induction chemotherapy in locally advanced T4b oral cavity squamous cell cancers: a regional cancer center experience. Indian J Cancer. 2017;54:35.

95. Joshi A, Patil VM, Noronha V, et al. Is there a role of induction chemotherapy followed by resection in T4b oral cavity cancers? Indian J Cancer. 2013;50:349.

96. Patil VM, Prabhash K, Noronha V, et al. Neoadjuvant chemotherapy followed by surgery in very locally advanced technically unresectable oral cavity cancers. Oral Oncol. 2014;50:1000-4. 
97. Rudresha A, Chaudhuri T, Lakshmaiah K, et al. Induction chemotherapy in technically unresectable locally advanced $\mathrm{T} 4 \mathrm{a}$ oral cavity squamous cell cancers: experience from a regional cancer center of South India. Indian J Med Paediatr Oncol. 2017;38:490.

98. Patil VM, Noronha V, Joshi A, et al. Induction chemotherapy in technically unresectable locally advanced oral cavity cancers: does it make a difference? Indian J Cancer. 2013;50:1-8.

99. Lin JC, Jan JS, Hsu CY, Wong DYK. High rate of clinical complete response to weekly outpatient neoadjuvant chemotherapy in oral carcinoma patients using a new regimen of cisplatin, 5-fluorouracil, and bleomycin alternating with methotrexate and epirubicin. Cancer. 1999;85:1430-8.

100. Price KAR, Nichols AC, Shen CJ, et al. Novel strategies to effectively de-escalate curativeintent therapy for patients with $\mathrm{HPV}$-associated oropharyngeal cancer: current and future directions. 2020 Asco Educational Book. https://doi.org/10.1200/EDBK_280687.

101. Marur S, Li S, Cmelak AJ, et al. E1308: phase II trial of induction chemotherapy followed by reduced-dose radiation and weekly cetuximab in patients with HPV-associated resectable squamous cell carcinoma of the oropharynx-ECOG-ACRIN cancer research group. J Clin Oncol. 2016;35:490-7.

102. Misiukiewicz K, Gupta V, Miles BA, et al. Standard of care vs reduced-dose chemoradiation after induction chemotherapy in HPV+ oropharyngeal carcinoma patients: the quarterback trial. Oral Oncol. 2019;95:170-7.

103. Seiwert TY, Foster CC, Blair EA, et al. OPTIMA: a phase II dose and volume deescalation trial for human papillomavirus-positive oropharyngeal cancer. Ann of Oncol. 2019;297-302(2019):30.

104. Rosenberg A, Agrawal N, Pearson AT, et al. Dose and volume de-escalation for HPVassociated oropharyngeal cancer: long-term follow-up of the OPTIMA trial. J Clin Oncol. 2020;38(suppl):Abstr 6575.

105. Gillison ML, Trotti AM, Harris J, et al. Radiotherapy plus cetuximab or cisplatin in human papillomavirus-positive oropharyngeal cancer (NRG oncology RTOG 1016): a randomised, multicentre, non-inferiority trial. Lancet. 2019;393:40-50.

106. Mehanna H, Robinson M, Hartley A, et al. Radiotherapy plus cisplatin or cetuximab in lowrisk human papillomavirus-positive oropharyngeal cancer (De-ESCALaTE HPV): an openlabel randomised controlled phase 3 trial. Lancet. 2019;393:51-60.

107. Sun XS, Michel C, Babin E, et al. Approach to oligometastatic disease in head and neck cancer, on behalf of the GORTEC. Future Oncol. 2018;14:877-89.

108. Noone AM, Howlader N, Krapcho M et al. SEER cancer statistics review, 1975-2015, National Cancer Institute. Bethesda, MD, https://seer.cancer.gov/csr/1975_2015/, based on November 2017 SEER data submission, posted to the SEER web site, April 2018.

109. Thomas TV, Packianathan S, Bhanat E, et al. Oligometastatic head and neck cancer: comprehensive review. Head Neck. 2020:1-8.

110. Vermorken JB, Mesia R, Rivera F, et al. Platinum-based chemotherapy plus cetuximab in head and neck cancer. N Engl J Med. 2008;111611-27:359.

111. Schulz D, Wirth M, Piontek G, et al. Improved overall survival in head and neck cancer patients after specific therapy of distant metastases. Eur Arch Otorhinolaryngol. 2018;275:1239-47.

112. Zumsteg ZS, Luu M, Yoshida EJ, et al. Combined high intensity local treatment and systemic therapy in metastatic head and neck squamous cell carcinoma: an analysis of the National Cancer Data Base. Cancer. 2017;123:4583-93.

113. Szturz P, Vermorken JB. Management of recurrent and metastatic oral cavity cancer: raising the bar a step higher. Oral Oncol. 2020;101:104492.

114 Haddad RI, Posner M, Hitt R, et al. Induction chemotherapy in locally advanced squamous cell carcinoma of the head and neck: role, controversy, and future directions. Ann Oncol. 2018;29:1130-40. 
115. Vermorken JB. Multidisciplinary decision making and head and neck tumor boards. In: Vermorken JB, Budach V, Leemans CR, Machiels JP, Nicolai P, O'Sullivan B, editors. Critical issues in head and neck oncology. Switzerland: Springer Nature; 2017. p. 99-108.

116. Leroy R, Silversmit G, Stordeur S, et al. Improved survival in patients with head and neck cancer treated in higher volume Centres: a population-based study in Belgium. Eur J Cancer. 2020;130:81-91.

117. Wuthrick EJ, Zhang Q, Machtay M, et al. Institutional clinical trial accrual volume and survival of patients with head and neck cancer. J Clin Oncol. 2015;33:156-64.

Open Access This chapter is licensed under the terms of the Creative Commons Attribution 4.0 International License (http://creativecommons.org/licenses/by/4.0/), which permits use, sharing, adaptation, distribution and reproduction in any medium or format, as long as you give appropriate credit to the original author(s) and the source, provide a link to the Creative Commons license and indicate if changes were made.

The images or other third party material in this chapter are included in the chapter's Creative Commons license, unless indicated otherwise in a credit line to the material. If material is not included in the chapter's Creative Commons license and your intended use is not permitted by statutory regulation or exceeds the permitted use, you will need to obtain permission directly from the copyright holder.

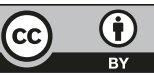

